\title{
Surface Engineering of Copper Foils for Growing Centimeter-Sized Single-Crystalline Graphene
}

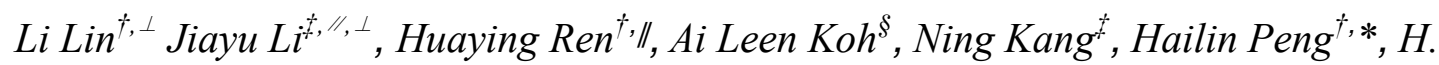
Q. Xu $\stackrel{\dot{f}, *}{ }$, and Zhongfan $\operatorname{Liu}^{\dagger, *}$

${ }^{\dagger}$ Center for Nanochemistry, Beijing Science and Engineering Center for Nanocarbons, Beijing National Laboratory for Molecular Sciences, College of Chemistry and Molecular Engineering, Peking University, Beijing 100871, P. R. China

${ }^{\ddagger}$ Key Laboratory for the Physics and Chemistry of Nanodevices and Department of Electronics, Peking University, Beijing 100871, P. R. China

${ }^{\S}$ Stanford Nano Shared Facilities, Stanford University, Stanford, California 94305, USA

"Academy for Advanced Interdisciplinary Studies, Peking University, Beijing 100871, China

Materials and Methods

$\underline{\mathrm{Cu} \text { foil pretreatment, graphene growth and transfer }}$

Commercially available copper foil (Alfa-Aesar \#46365, \#46986) was 
electrochemically polished to clean and flatten the surface. Note that, the electrochemically polishing is not prominent in controlling the nucleation density of graphene grains as the melamine treatment. Graphene was synthesized on $\mathrm{Cu}$ foil in a low pressure CVD (LPCVD) system equipped with a 1-inch-diameter quartz tube. The $\mathrm{Cu}$ foil was loaded into hot center of furnace, while $1 \mathrm{~g}$ melamine powder $\left(\mathrm{C}_{3} \mathrm{~N}_{6} \mathrm{H}_{6}, 98 \%\right.$ purity, J\&K Scientific) was placed upstream at a location 40 -cm away from the hot center. A schematic of experimental setup was shown in Figure. S1a. For the graphene growth process, the system was heated to $1020{ }^{\circ} \mathrm{C}$ under a $\mathrm{H}_{2}$ flow of $100-\mathrm{cm}^{3}$ per min $(\mathrm{sccm})$, corresponding to $110 \mathrm{~Pa}$. The annealing was carried out at $1020{ }^{\circ} \mathrm{C}$ for $1 \mathrm{~h}$ to eliminate the surface oxygen and contamination. Before introducing $\mathrm{CH}_{4}$, melamine powders were heated with a heating tape to $120{ }^{\circ} \mathrm{C}$ for the gradual sublimation, with $100 \mathrm{sccm}$ pure Ar as carrier gas for the transportation of the melamine downstream to the $\mathrm{Cu}$ foil at the hot center with a corresponding pressure $150 \mathrm{~Pa}$. The thermal Gravimetric Analyzer (TGA) of the melamine at atmosphere pressure is presented in Figure. S2. To be noted here, there would be no prominent reduction of nucleation density, if hydrogen is used as carrier gas, due to the reaction between hydrogen and carbon- and nitrogen-containing compound. The melamine was used with exposure time ranging from $3 \mathrm{~min}$ to $15 \mathrm{~min}$. Subsequently, the methane and hydrogen were introduced into the CVD system for the graphene growth at $1020{ }^{\circ} \mathrm{C}$ under different $\mathrm{H}_{2}: \mathrm{CH}_{4}$ ratios (10-6000) with corresponding chamber pressure ranging from 10 to $600 \mathrm{~Pa}$. The typical $\mathrm{P}_{\mathrm{CH} 4}$ range is from $0.1 \mathrm{~Pa}$ to $1 \mathrm{~Pa}$, and the time for graphene growth varied from $3 \mathrm{~min}$ to $36 \mathrm{~h}$. Notably, the nucleation 
density can be reduced to less than $10^{-2} \mathrm{~mm}^{-2}$ for growth of centimeter-sized single-crystal graphene at the $\mathrm{H}_{2}: \mathrm{CH}_{4}$ ratio=5000, with $\mathrm{P}_{\mathrm{CH} 4}=0.1 \mathrm{~Pa}$, a total pressure $600 \mathrm{~Pa}$. After growth, the system was cooled down to room temperature while still under the same flow. The typically integrated growth procedure is shown in Figure. S1b.

The individual graphene domains or continuous films were transferred onto $\mathrm{SiO}_{2} / \mathrm{Si}$ substrates, using poly(methyl methacrylate) (PMMA)-assisted wet ${ }^{1,2}$ or dry method ${ }^{3}$ for Raman characterizations and electrical device fabrication. The graphene was grown on both sides of the copper foils, and one side of the graphene used for characterization was spin-coated with PMMA and baked at $150{ }^{\circ} \mathrm{C}$ for $5 \mathrm{~min}$. Then, the other side of the sample was exposure to $\mathrm{O}_{2}$ plasma for $3 \mathrm{~min}$ to remove the graphene. Subsequently, the $1 \mathrm{M} \mathrm{Na}_{2} \mathrm{~S}_{2} \mathrm{O}_{8}$ solution was applied to etch the copper away. Then the free-standing PMMA/graphene membrane floating on the surface of the etching solution was washed with deionized water three times, and then transferred onto target substrate. After drying, the PMMA was dissolved by acetone yielding graphene domains or continuous film on substrate. The "dry transfer" method was also used to transfer graphene to avoid the p-doping effect caused by the adsorbed $\mathrm{H}_{2} \mathrm{O}$ and $\mathrm{O}_{2}$ from air. In "dry transfer" method, after rinsed by deionized water, the PMMA/graphene was subsequently washed by isopropanol and then dried in air for $12 \mathrm{~h}$ before it was placed onto the target substrates.

\section{Characterizations of single-crystal graphene}


The morphology and structure of the grown graphene on $\mathrm{Cu}$ foil or on dielectric substrate were characterized with optical microscopy (Olympus BX51), SEM (Hitachi S-4800, acceleration voltage 5-30 kV) and Raman spectrum (Horiba, LabRAM HR-800, 514 laser wavelength, $\times 100$ objective). The graphene domain on amorphous carbon-covered TEM grid was characterized by TEM (FEI Tecnai T20, acceleration voltage $200 \mathrm{kV}$ ). Aberration-corrected TEM studies were performed using an FEI 80-300 Environmental Titan operated in monochromated mode at $80 \mathrm{kV}$. The element analysis of $\mathrm{Cu}$ foil at stages of entire growth process was characterized by AES and XPS (Kratos Analytical AXIS-Ultra with monochromatic Al K $\alpha$ X-ray).

The fabricated devices were characterized by AFM (Veeco dimension 3100), before electrical characterization. Electric transport at room temperature were carried out in a vacuum probe station (Lakeshore TTP-4), using Keithly Semiconductor Characterization System (Model 4200-SCS). Electric transport and magneto transport-measurements at low temperatures were performed in a Physical Property Measurement System (Quantum Design, DynaCool) and a ${ }^{3} \mathrm{He} /{ }^{4} \mathrm{He}$ dilution refrigerator (Oxford, Triton 200), via a standard lock-in technique (Stanford) respectively.

\section{Supplementary Text}

Control experiments used to confirm the passivation effect of the melamine pretreatments

In the following experiments, the growth parameters other than $\mathrm{H}_{2}: \mathrm{CH}_{4}$ ratios and 
exposure time (pretreatment time) of melamine were kept the same. And the growth is halted before the full coverage of graphene on $\mathrm{Cu}$ foil. Thus, we can counts the nucleation density of graphene and deduce the nucleation preference of graphene from the growth results.

(1) The accumulation of graphene grains on $\mathrm{Cu}-\mathrm{GBs}$ at different $\mathrm{H}_{2}: \mathrm{CH}_{4}$ ratios

The annealing was performed in hydrogen with flow rate $100 \mathrm{sccm}$ at $1020{ }^{\circ} \mathrm{C}$ for 1 h, and then $\mathrm{H}_{2}$ and $\mathrm{CH}_{4}$ were subsequently introduced to the CVD system with $\mathrm{H}_{2}: \mathrm{CH}_{4}$ ratio=200 and $500\left(\mathrm{P}_{\mathrm{CH} 4}=0.1 \mathrm{~Pa}\right)$, respectively. The growth time of graphene grains is $10 \mathrm{~min}$. The growth results of graphene grains with are shown in Figure. S3 and Figure. S4 respectively, which clearly shows a prominent accumulation of graphene grains on the $\mathrm{Cu}-\mathrm{GBs}$, without the melamine pretreatments.

(2) Change of nucleation preference of graphene on the pretreated copper foils at different $\mathrm{H}_{2}: \mathrm{CH}_{4}$ ratio

The annealing was performed in hydrogen with flow rate $100 \mathrm{sccm}$ at $1020{ }^{\circ} \mathrm{C}$ for 1 h. Before the initiation of graphene growth melamine was firstly introduced onto the polycrystalline copper foil, through sublimation and subsequent transportation of melamine, in which Ar was used as carrier gas, with pretreatment time of melamine set to 10 min. $\mathrm{H}_{2}$ and $\mathrm{CH}_{4}$ were subsequently introduced to the CVD system with $\mathrm{H}_{2}: \mathrm{CH}_{4}$ ratio=200 and $500\left(\mathrm{P}_{\mathrm{CH} 4}=0.1 \mathrm{~Pa}\right)$, respectively. The growth results of graphene grains with are shown in Figure. S8 and Figure. S6.These clearly indicate a sharp change of the nucleation preference of graphene on the treated $\mathrm{Cu}$ foil, in which, 
graphene can only nucleate on the flattened surface instead of the $\mathrm{Cu}-\mathrm{GBs}$.

(3) The nucleation preference of graphene grains (on $\mathrm{Cu}-\mathrm{GBs}$ or flattened surface) on treated or untreated copper foil as a function of $\mathrm{H}_{2}: \mathrm{CH}_{4}$ ratio

Control experiments were conducted to grow graphene on treated or untreated copper foil, at different $\mathrm{H}_{2}: \mathrm{CH}_{4}$ ratios. The annealing was performed in hydrogen with flow rate $100 \mathrm{sccm}$ at $1020{ }^{\circ} \mathrm{C}$ for $1 \mathrm{~h}$. Before the initiation of graphene growth melamine was firstly introduced onto the polycrystalline copper foil, through sublimation and subsequent transportation of melamine, with the pretreatment time set to10 min. Subsequently $\mathrm{H}_{2}$ and $\mathrm{CH}_{4}$ were directly added to the CVD system with different $\mathrm{H}_{2}: \mathrm{CH}_{4}$ ratios. For contrast, the graphene was grown by the same procedure without melamine pretreatments under the same $\mathrm{H}_{2}: \mathrm{CH}_{4}$ ratios. To get statistical preference of graphene nucleation, the nucleation density at $\mathrm{Cu}-\mathrm{GBs}$ and flat surface on treated or untreated copper foil were counted respectively, and the corresponding ratio is shown in Figure. 1e.

Control experiments were also conducted to further reduce the nucleation density of graphene grains

(1) The influence of the pretreatment time on nucleation density of graphene grains

The annealing was performed in hydrogen with flow rate $100 \mathrm{sccm}$ at $1020^{\circ} \mathrm{C}$ for 1 h. Before the initiation of graphene growth melamine was firstly introduced onto the polycrystalline copper foil, through sublimation and subsequent transportation of 
melamine. The time used for heating melamine by heat tape for following subsequent sublimation and transportation, which means the pretreatment time, is set to 0 (no pretreatment), 3, 5, 7, 9, 11,13 min, respectively. Subsequently $\mathrm{H}_{2}$ and $\mathrm{CH}_{4}$ were added to the CVD system for graphene growth with $\mathrm{H}_{2}: \mathrm{CH}_{4}$ ratios. After growth, to get statistical results about influence of pretreatment time on the nucleation density of graphene grains, the graphene grains, shown in Figure. 8 were counted in area of at least $2 \mathrm{~mm} * 2 \mathrm{~mm}$. The corresponding statistical results is shown in Figure. S9.

(2) The influence of $\mathrm{H}_{2}: \mathrm{CH}_{4}$ ratio on nucleation density of graphene grains

The annealing was performed in hydrogen with flow rate $100 \mathrm{sccm}$ at $1020^{\circ} \mathrm{C}$ for 1 h. Before the initiation of graphene growth melamine was firstly introduced onto the polycrystalline copper foil, through sublimation and subsequent transportation of melamine, in which Ar was used as carrier gas, with pretreatment time of melamine set to $10 \mathrm{~min}$. Subsequently, $\mathrm{H}_{2}$ and $\mathrm{CH}_{4}$ were added to the $\mathrm{CVD}$ system for graphene growth with certain $\mathrm{H}_{2}: \mathrm{CH}_{4}$ ratios ranging from 20 to 6000 . And to do the contrast, the graphene was grown on untreated $\mathrm{Cu}$ foil at the same $\mathrm{H}_{2}: \mathrm{CH}_{4}$ ratio, After growth, to get statistical results about the influence of $\mathrm{H}_{2}: \mathrm{CH}_{4}$ ratios on the nucleation density of graphene grains on treated and untreated $\mathrm{Cu}$ foil, the graphene nuclei were counted in area of at least $2 \mathrm{~mm} * 2 \mathrm{~mm}$. The statistical results and corresponding SEM image of typical growth results are shown in Figure. S10 (on untreated Cu foil) and Figure. $\mathrm{S} 11$ (on treated $\mathrm{Cu}$ foil).

Optical images and Raman spectra of graphene domains 
The Raman spectras of graphene domains transferred onto $\mathrm{SiO}_{2} / \mathrm{Si}$ were acquired by using $514 \mathrm{~nm}$ excitation laser with a $\times 100$ objective lens. Determined by $\mathrm{H}_{2}: \mathrm{CH}_{4}$ ratios, graphene domains in both compact and dendritic shapes were grown and observed by using OM (Figure. S13 and Figure. S14). We attribute the different growth kinetics (diffusion limited and edge-attachment limited) to the difference in domain shapes. ${ }^{4-6}$ The Raman spectra of the compact and dendritic graphene domains, shown in Figure. S13d and Figure. S14b, indicate the single layer nature of graphene grains with weak D bands only presenting at the edges of the domains. The uniform contrast of large graphene single crystals shown in Figure. S13a, also suggest that the graphene domain was almost of uniform thickness along with some small multilayer domains (Figure. S13b), which is corroborated by broader 2D peak of Raman spectra (Figure. S13d $)^{7}$.

To exclude possibility of incorporation of nitrogen atoms into graphene lattices, Acontinuous as-grown graphene film was transferred to silicon substrate with $300 \mathrm{~nm}$ thick $\mathrm{SiO}_{2}$, as shown by the optical picture (Figure. S15a). Figure. S15b shows single-point Raman spectra collected at 10 locations selected randomly, exhibiting no presence of D band, which confirms absence of foreign atoms. The Raman mapping also were conducted at representative locations on this sample as marked in Figure. S15a and the maps of signals around $1585 \mathrm{~cm}^{-1}$ (G peak) and signal around $1350 \mathrm{~cm}^{-1}$ are shown in Figures. S15c-f and Figures. S15g-j, respectively, justifying the absence of nitrogen-related D band. These observations provide additional spectroscopic proof of formation of perfect graphene without incorporation of nitrogen atoms. 
Additionally, XPS analyses of transferred graphene films have been conducted. To enhance the corresponding signals of specific elements in XPS, as-grown single-layer graphene films which was carefully transferred onto $\mathrm{Si} / \mathrm{SiO}_{2}$ substrate five and ten times to form a multiple layer graphene films (Inset of Figure. S16a). As shown Figure. S16, no detectable signal of nitrogen element was found from the XPS result.

\section{$\underline{\text { Transport property measurements }}$}

(1) Device fabrication and electric measurements

The graphene samples were transferred onto $\mathrm{SiO}_{2} / \mathrm{Si}$ substrates with marks for alignments, then followed by heat cleaning and AFM imaging to check the flatness of the samples. After that, the graphene samples were etched into Hall bar geometry by using a PMMA etch mask (PMMA 950K A2 @ 4000 rpm) from Electron Beam Lithography (EBL) (Raith 150 2nd) and Reactive Ion Etching (RIE) $\mathrm{O}_{2}$ etching (Trion technology minilock III). After the samples were patterned, a second time AFM imaging was performed to ensure that the channel regions were free of winkles and residues. Finally, after using EBL to design a PMMA mask (PMMA 950K A4 @ 4000 rpm), the samples were contacted with $5 \mathrm{~nm} \mathrm{Ti}$ and $90 \mathrm{~nm} \mathrm{Au}$ by using the electron-beam evaporator (Kurte J. Lesker AXXIS) and followed by a standard metal lift-off technique.

(2) Nonlinear fitting method for field-effect (FET) mobility:

The carrier density (electrons or holes) in the graphene channel regions $n_{\text {tot }}$ can be approximated $^{8}$ by 


$$
n_{t o t}=\sqrt{n\left[V_{g}\right]^{2}+n_{0}^{2}}
$$

Where $\mathrm{n}_{0}$ represents the density of carriers at Dirac point, named residual carrier density.

In the two terminal method, metal/graphene contact resistance should be taken into account during the fitting

$$
R_{\text {tot }}=R_{\text {contact }}+R_{\text {channel }}=R_{\text {contact }}+\frac{L}{W} \frac{1}{\text { eu } \sqrt{n\left[V_{g}\right]^{2}+n_{0}^{2}}}
$$

Where $\mathrm{R}_{\text {contact }}$ represents contact resistance, $L$ and $W$ represent channel length and weight, and $u$ represents the FET mobility.

Ignoring the quantum capacitance, gate induced carrier density can be calculated by

$$
n\left[V_{g}\right]=\frac{C_{o x} *\left(V_{g}-V_{\text {dirac }}\right)}{e}
$$

In the four terminal method, contact resistance could be eliminated, then $\mathrm{R}_{\text {tot }}$ can be written as

$$
R_{\text {tot }}=R_{\text {channel }}=\frac{L^{\prime}}{W} \frac{1}{\text { eu } \sqrt{n\left[V_{g}\right]^{2}+n_{0}^{2}}}
$$

Where $L^{\prime}$ is the length between two bars.

(3) Hall mobility:

The hall mobility can be extracted by

$$
u=\frac{L}{W} \frac{R_{x y} / R_{x x}}{B}
$$


at the low magnetic field (from $-0.5 \mathrm{~T}$ to $0.5 \mathrm{~T}$ ).

\section{Spatially resolved elemental analysis of the copper surface at stages of growing} $\underline{\text { large single crystals of graphene }}$

To better understand the underlying mechanism of melamine pretreatments, AES point element analysis and element mapping analysis were conducted on copper foils at stages of the whole growth process. After each stage, copper foils were quickly removed from the hot center of furnace and cooled down to room temperature for AES characterization. The SEM image and corresponding spatially resolved AES elemental analysis, single-point analysis and mapping analysis, would provide the spatial distribution and concentration of the carbon- and nitrogen-containing compound on treated copper. The SEM image of the millimeter-sized copper foil just after the melamine pretreatment for AES characterization is displayed in Figure. S20a, exhibiting a brighter contrast at the copper grain boundaries, which is indicative of the presence of carbon and nitrogen atoms. Figures. S20b-m present the enlarged AES map of specific element and corresponding SEM images, clearly exhibiting a higher concentration of carbon and nitrogen at copper grain boundaries compared to that on the flat surface. These observations verify the accumulation of nitrogen-containing species at copper grain boundaries after the melamine pretreatment, which would passivate these active sites. Furthermore, single-point analysis would give more convincing information about the nitrogen concentration, by using twenty analysis cycles to enhance the signal-to-noise ratio. The release of carbon- and nitrogen-containing compound was also evidenced by AES mapping of the copper foil 
(Figure. S21). In detail, after nucleation, when graphene domain grows across the $\mathrm{Cu}-\mathrm{GBs}$, the nitrogen element is not detectable from AES mapping results, which suggest the complete release of carbon- and nitrogen-containing compound (Figure. S21c).

To identify structural information of the species formed on the copper surface, the XPS is informative with the respect of the concentration and the bonding type of specific elements, which indicates the as-formed species from melamine evaporation contain the carbon and nitrogen element (atomic percentage 19.8\%) with the various bonding types (peaks related to nitrogen atoms bonded to $\mathrm{sp}^{2}$-hybridised carbon and $\mathrm{p}^{3}$ carbon) (Figures. S19a,b). Furthermore, the IR spectra of the species, shown in Figure. S19c, exhibit prominent absorption of $\mathrm{C}=\mathrm{N}$ and $\mathrm{C}-\mathrm{N}$ bonding, verifying the formation of carbon- and nitrogen-containing species. Thus, we believe that the decomposition of melamine and subsequent formation of carbon and nitrogen-containing species should happen at high temperature $\left(1020{ }^{\circ} \mathrm{C}\right)$ in the CVD growth system ${ }^{9}$. 


\section{Reference}

1 Li, X.; Cai, W.; An, J.; Kim, S.; Nah, J.; Yang, D.; Piner, R.; Velamakanni, A.;

Jung, I.; Tutuc, E. Large-Area Synthesis of High-Quality and Uniform Graphene Films on Copper Foils. Science 2009, 324, 1312-1314.

2 Reina, A.; Son, H.; Jiao, L.; Fan, B.; Dresselhaus, M. S.; Liu, Z. F.; Kong, J. Transferring and Identification of Single-and Few-Layer Graphene on Arbitrary Substrates. J. Phys. Chem. C. 2008, 112, 17741-17744.

3 Petrone, N.; Dean, C. R., Meric, I.; van der Zande, A. M.; Huang, P. Y.; Wang, L.; Muller, D.; Shepard, K. L. Chemical Vapor Deposition-Derived Graphene with Electrical Performance of Exfoliated Graphene. Nano lett. 2012, 12, 2751-2756.

4 Zhang, X.; Wang, L.; Xin, J.; Yakobson, B. I.; Ding, F. Role of Hydrogen in Graphene Chemical Vapor Deposition Growth on a Copper Surface. J. Am. Chem. Soc. 2014, 136, 3040-3047.

5 Meca, E.; Lowengrub, J.; Kim, H.; Mattevi, C.; Shenoy, V. B. Epitaxial Graphene Growth and Shape Dynamics on Copper: Phase-Field Modeling and Experiments. Nano lett. 2013. 13, 5692-5697.

6 Artyukhov, V. I.; Liu, Y.; Yakobson, B. I. Equilibrium at the Edge and Atomistic Mechanisms of Graphene Growth. Proc. Natl. Acad. Sci. 2012, 109, 15136-15140.

7 Hao, Y.; Wang, Y.; Wang, L.; Ni, Z.; Wang, Z.; Wang, R.; Koo, C. K.; Shen, Z.; Thong, J. T. L. Probing Layer Number and Stacking Order of Few - Layer Graphene by Raman Spectroscopy. Small 2010, 6, 195-200.

8 Kim, S.; Nah, J.; Jo, I.; Shahrjerdi, D.; Colombo, L.; Yao, Z.; Tutuc, E.; Banerjee, 
S. K. Realization of a High Mobility Dual-Gated Graphene Field-Effect Transistor with $\mathrm{Al}_{2} \mathrm{O}_{3}$ Dielectric. Appl. Phy. Lett. 2009, 94, 062107.

9 Muhl, S.; Méndez, J. M. A Review of the Preparation of Carbon Nitride Films.

Diamond. Relat. Mater. 1999, 8, 1809-1830 

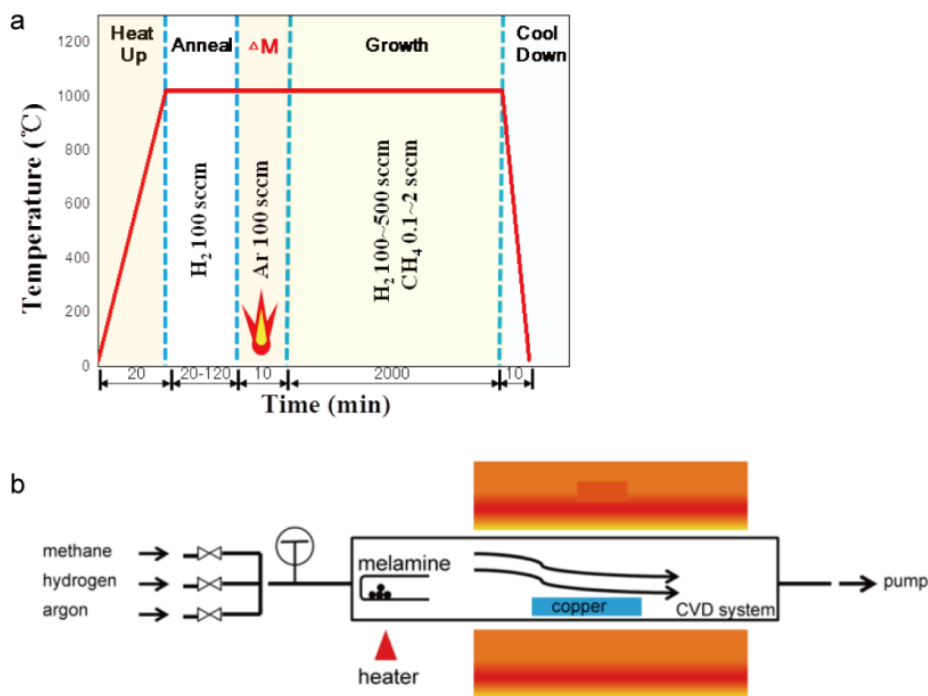

Figure S1. Drawing of CVD system and growth procedure. (a) Growth procedure of growing large-single crystal graphene. The growth time of graphene varied from 3 min to $36 \mathrm{~h}$. The pretreatment time was set to $10 \mathrm{~min}$, with $100 \mathrm{sccm}$ Ar as carrier gas. The $\mathrm{H}_{2}: \mathrm{CH}_{4}$ molar ratio varied for 10 to 6000 . The typical $\mathrm{P}_{\mathrm{CH} 4}$ range is from $0.1 \mathrm{~Pa}$ to $1 \mathrm{~Pa}$. (b) Drawing of the low-pressure CVD system, where the melamine was positioned upstream 40-cm away from the hot center. The heater is a heating tape with temperature set to $120{ }^{\circ} \mathrm{C}$

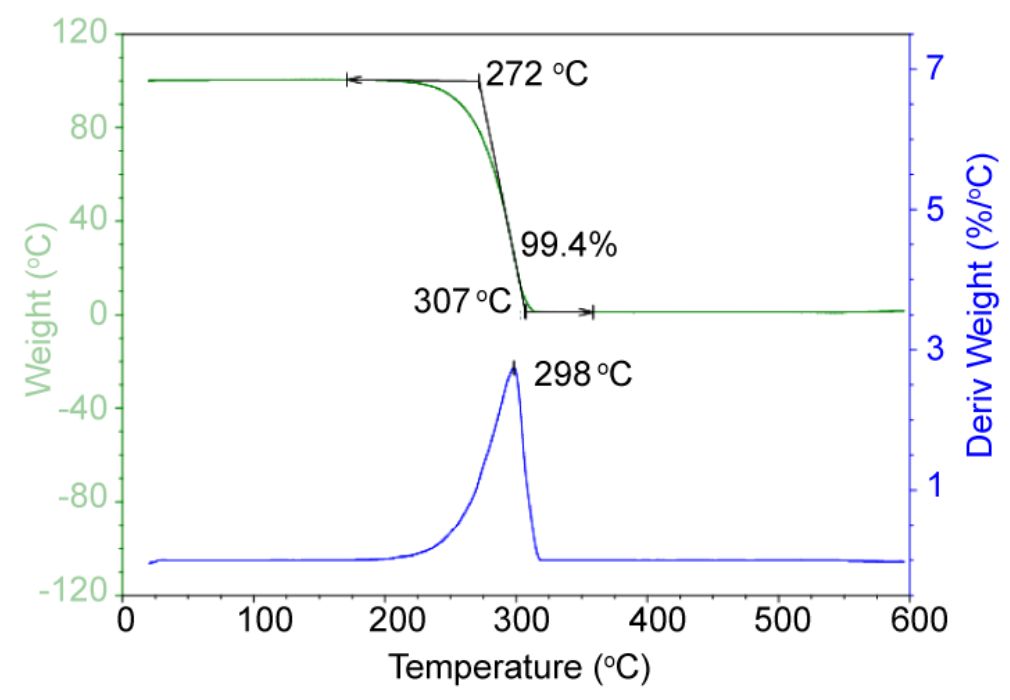

Figure S2. Profiles from simultaneous TGA-DSC thermal analysis of melamine at a 
heating rate of $10{ }^{\circ} \mathrm{C} / \mathrm{min}$.
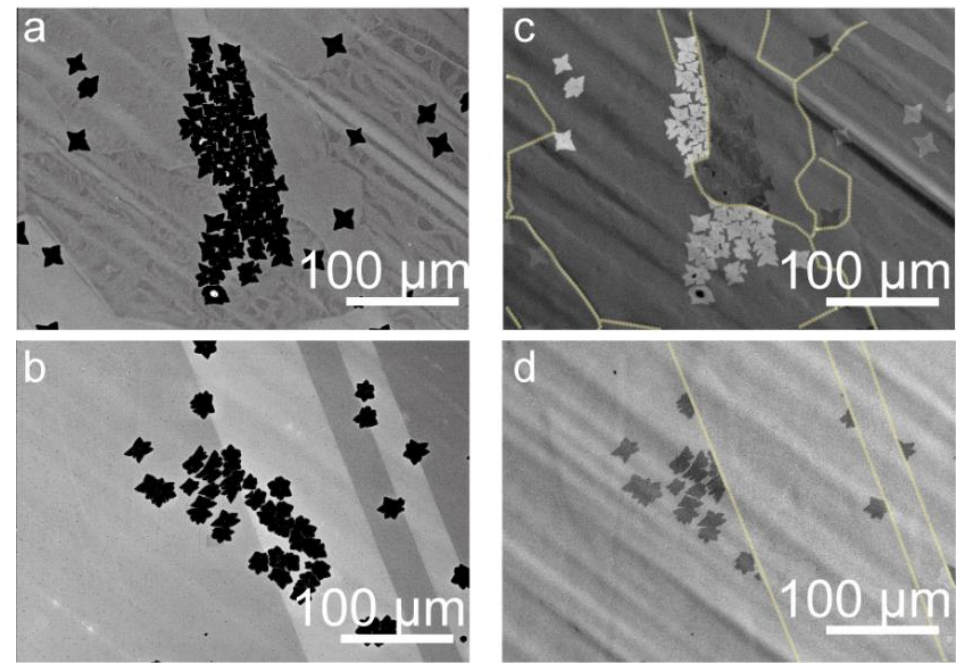

Figure S3. The accumulation of graphene grains on the Cu-GBs at different $\mathbf{H}_{2}: \mathbf{C H}_{4}$ ratios. $(\mathbf{a}, \mathbf{b})$ The SEM images in upper mode of graphene domains grown on untreated $\mathrm{Cu}$ foil at $\mathrm{H}_{2}: \mathrm{CH}_{4}$ molar ratio 200. (c,d) The SEM images in lower mode of $\mathrm{a}$ and $\mathrm{b}$ respectively. The yellow line denotes the presence of $\mathrm{Cu}-\mathrm{GBs}$.
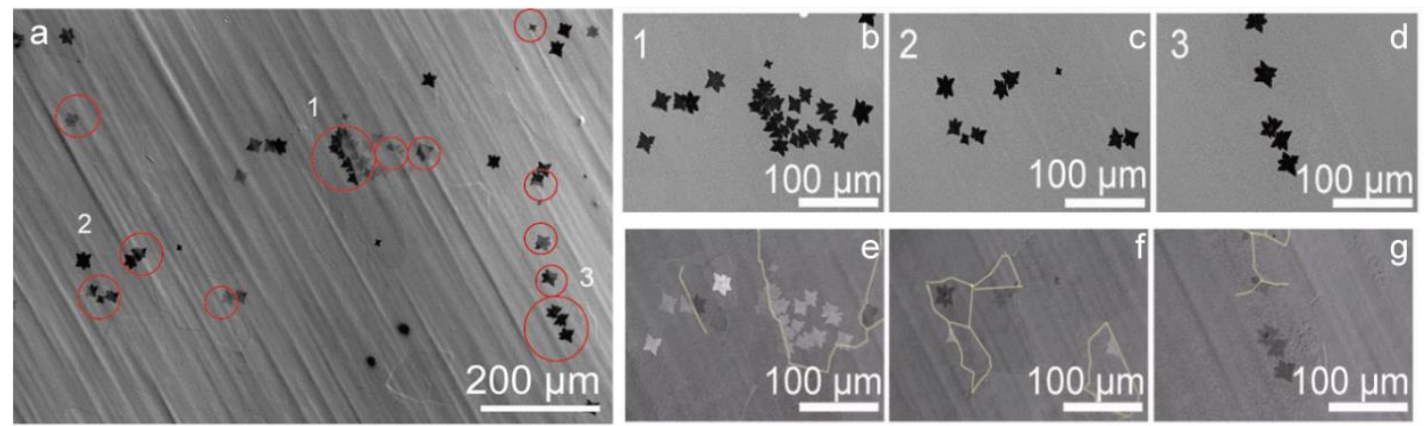

Figure S4. The accumulation of graphene grains on the Cu-GBs at different $\mathbf{H}_{2}: \mathbf{C H}_{4}$ ratios. (a) The SEM image in upper mode of graphene domains grown on untreated $\mathrm{Cu}$ foil at $\mathrm{H}_{2}: \mathrm{CH}_{4}$ ratio 500. The graphene domains inside the red circle indicate they are formed at the Cu-GBs. (b-d) high-magnification SEM images in upper mode of the 1, 2, 3 zones in a. (e-f) The SEM image in lower mode of b, c, d. 
The yellow line denotes the position of copper boundary.
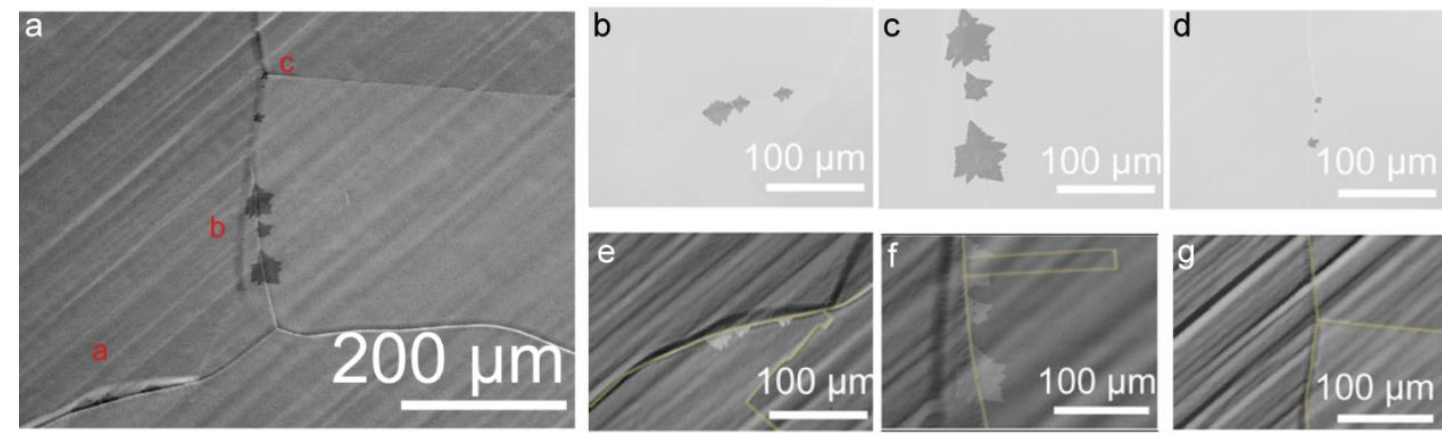

Figure S5. The accumulation of graphene grains on the Cu-GBs at different

$\mathbf{H}_{2}: \mathbf{C H}_{4}$ ratios. (a) The SEM image in upper mode of graphene domains grown on untreated $\mathrm{Cu}$ foil at $\mathrm{H}_{2}: \mathrm{CH}_{4}$ ratio 800. (b-d) High-magnification SEM images in upper mode of a, b, c, zones marked in (a). (e-g) The SEM images in lower mode of a, b, c, zones marked in (a). The yellow line denotes the presence of $\mathrm{Cu}-\mathrm{GBs}$.
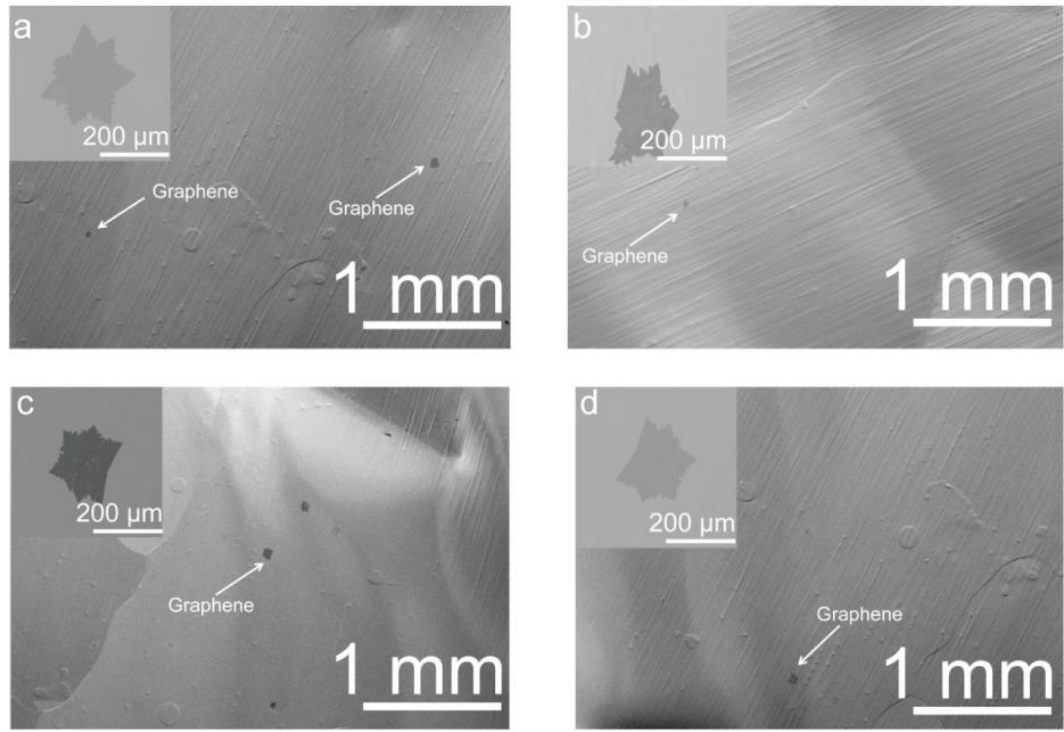

Figure S6. Change of nucleation preference of graphene on the pretreated $\mathrm{Cu}$ foil.

(a-d) The SEM images in upper mode of graphene domains grown on pretreated $\mathrm{Cu}$ 
foil at $\mathrm{H}_{2}: \mathrm{CH}_{4}$ ratio 800 . The pretreatment time is set to $10 \mathrm{~min}$. Insets: high-magnification SEM images of graphene grains.

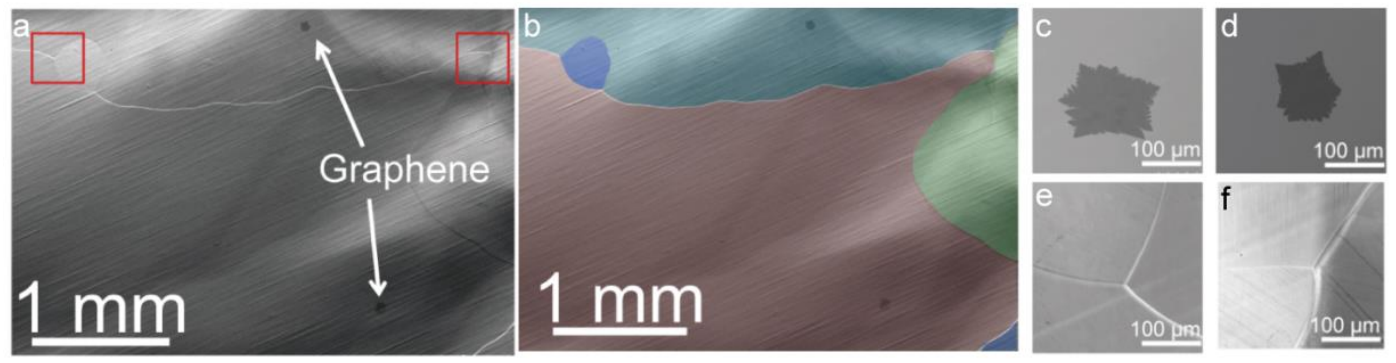

Figure S7. The overall reduced nucleation density of graphene grains on pretreated $\mathrm{Cu}$ foil. (a) The SEM image in upper mode of graphene domains grown on pretreated copper at $\mathrm{H}_{2}: \mathrm{CH}_{4}$ ratio 800 . The same image is shown in Fig. 1d. The pretreatment time is set to 10 min. (b) False coloured SEM image of a. The region of one single color indicates one copper grain. $(\mathbf{c}, \mathbf{d})$ High-magnification SEM images in upper mode of two graphene domains marked in (a). (e, f) The SEM images in lower mode of zones marked by red square in (a).
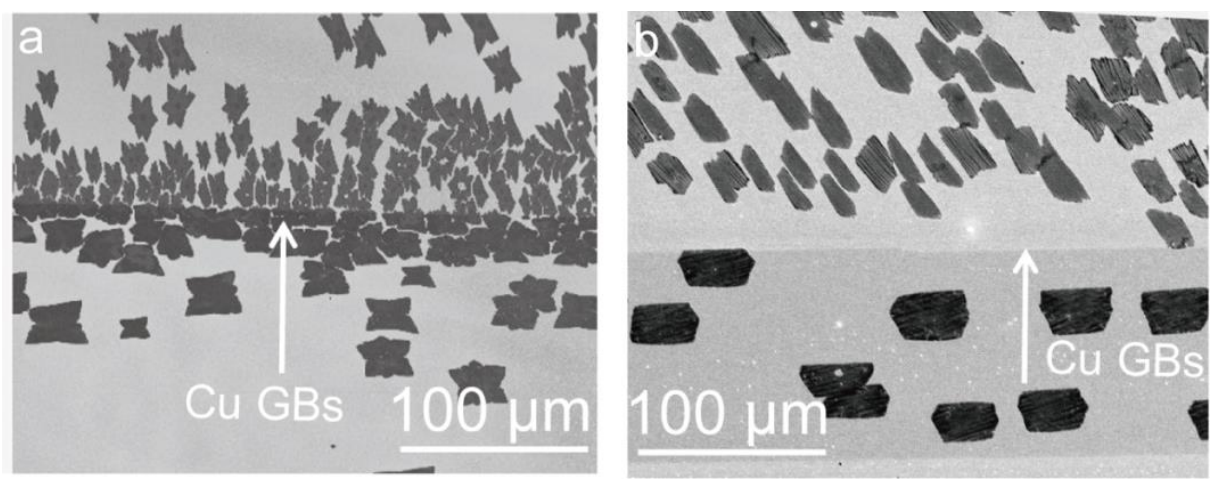

Figure S8. Change of nucleation preference of graphene on the pretreated $\mathrm{Cu}$ foil at lower $\mathrm{H}_{2}: \mathbf{C H}_{4}$ ratio. (a) The SEM image in upper mode of graphene domains grown on untreated copper at $\mathrm{H}_{2}: \mathrm{CH}_{4}$ ratio 200. (b) The SEM image in upper mode of 
graphene domains grown on pretreated $\mathrm{Cu}$ foil at $\mathrm{H}_{2}: \mathrm{CH}_{4}$ ratio 200 . The pretreatment time is set to $10 \mathrm{~min}$.
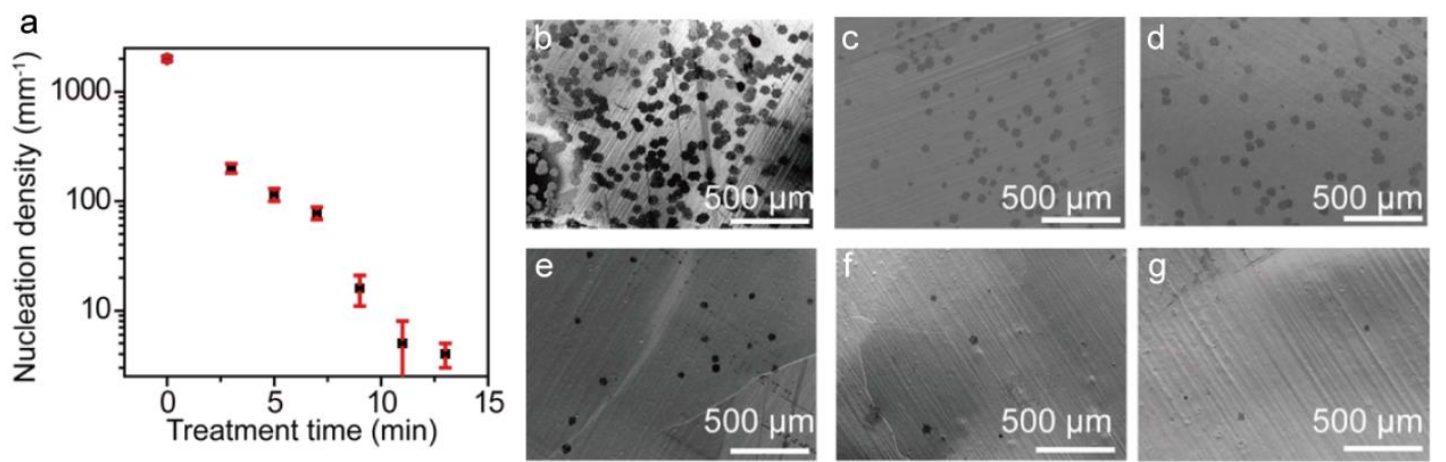

Figure S9. The nucleation density of graphene grains on pretreated $\mathrm{Cu}$ foil as a

function of pretreatment time. (a) The nucleation density of graphene grains on pretreated copper as a function of pretreatment time. The pretreatment time was set to 0 (no treatment), 3, 5, 7, 9, 11 and $13 \mathrm{~min}$. The $\mathrm{H}_{2}: \mathrm{CH}_{4}$ ratio was 200. (b-g) The typical SEM images in upper mode of graphene domains grown on pretreated $\mathrm{Cu}$ foil . The pretreatment is set to $0,3,5,7,9$ and 11 min respectively. The nucleation density would keep the same when the pretreatment time exceeds $10 \mathrm{~min}$, thus, the pretreatment time was set to $10 \mathrm{~min}$ in other experiments.
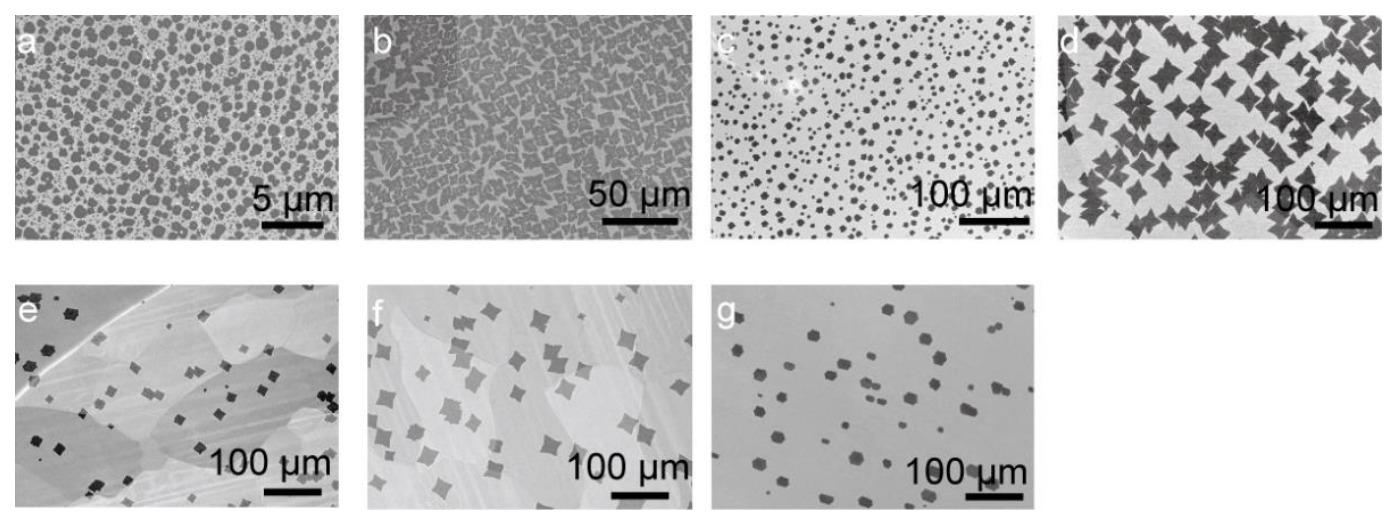
Figure S10. The nucleation density of graphene grains on untreated $\mathrm{Cu}$ foil as a function of $\mathbf{H}_{2}: \mathbf{C H}_{4}$ ratio. (a-g) The SEM images in upper mode of graphene domains grown on untreated copper at $\mathrm{H}_{2}: \mathrm{CH}_{4}$ ratio 20, 50, 100, 300, 550, 1500, 2000, respectively.
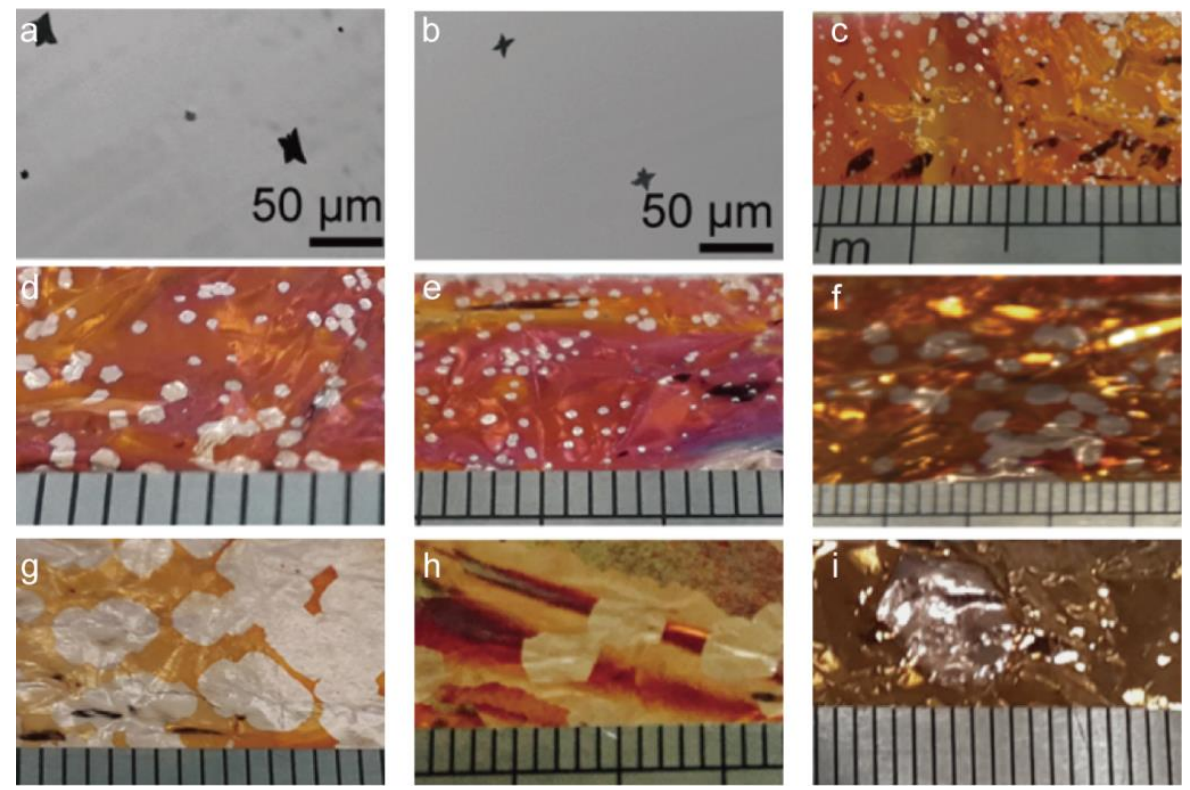

Figure S11. The nucleation density of graphene grains on pretreated $\mathrm{Cu}$ foil as a

function of $\mathbf{H}_{2}: \mathbf{C H}_{4}$ ratio. (a,b) The SEM images in upper mode of graphene domains grown on pretreated $\mathrm{Cu}$ foil at $\mathrm{H}_{2}: \mathrm{CH}_{4}$ molar ratio 20, 50. (c-i) The digital photos of graphene domains grown on pretreated $\mathrm{Cu}$ foil at $\mathrm{H}_{2}: \mathrm{CH}_{4}$ molar ratio 100 , $300,550,1500,2000,4000$, and 6000 , respectively. The pretreatment time is set to 10 $\min$. 


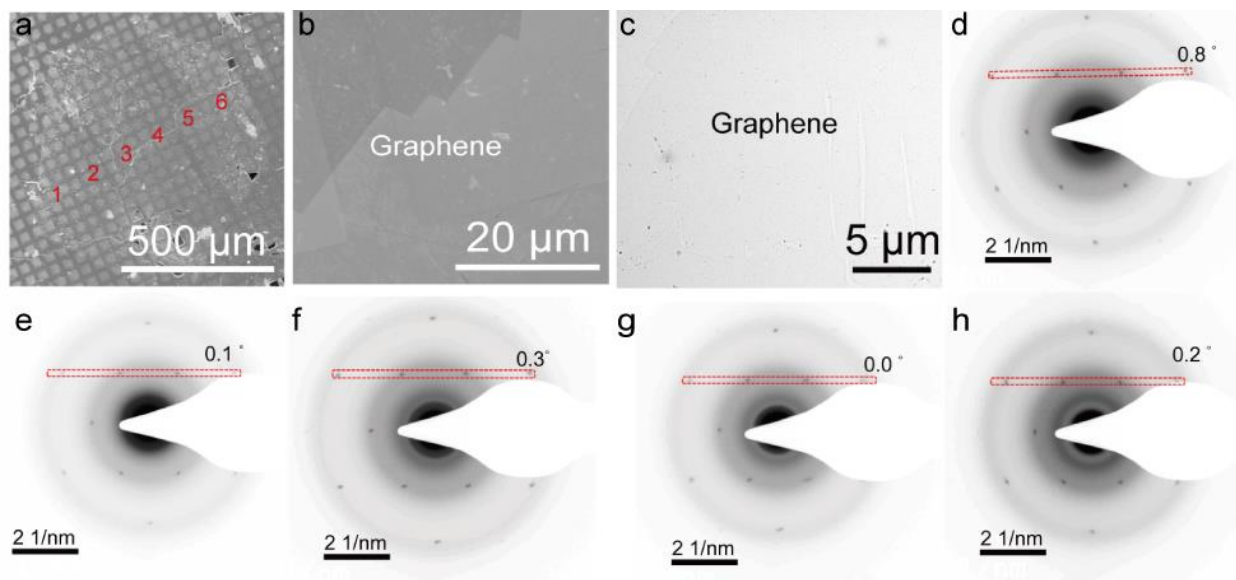

Figure S12. Structural characterization of large single-crystal graphene domain.

(a) SEM image of $1 \mathrm{~mm}$ graphene domain transferred onto an amorphous carbon-covered TEM grid. The same image is shown in Fig. 2a. (b) High-magnification SEM image of (a). (c) A bright-field TEM image of the graphene domain on the TEM grid. (d-h) Selective area electron diffraction (SAED) patterns taken from different positions, marked by 2, 3, 4, 5 and 6 respectively, and the SAED pattern of position 1 is shown in Fig. $2 b$.

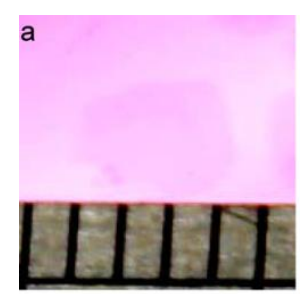

d

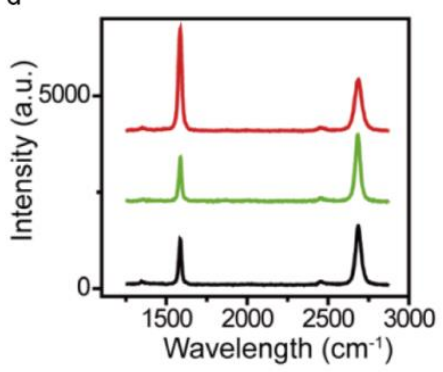

$\mathrm{SiO}_{2}$

○
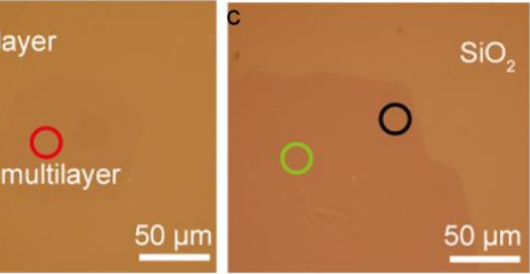

e

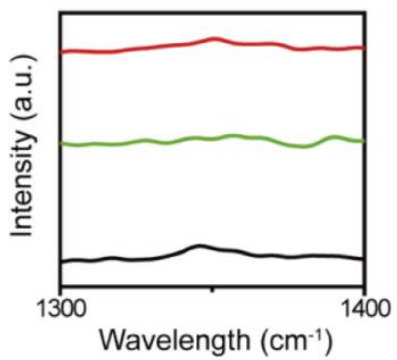

Figure S13. Optical images and Raman spectra of graphene domains in compact 
shape. (a) $\mathrm{OM}$ image of $3 \mathrm{~mm}$ graphene domain transferred onto $\mathrm{SiO}_{2} / \mathrm{Si}$ substrate. (b) High-magnification $\mathrm{OM}$ image of small multilayer domains in (a). (c) High-magnification OM image of edges of graphene domain in a. (d) Raman spectra of graphene domain from different positions marked by circles of different colors in (a) and (b). (e) The comparison of intensity of D peaks of Raman spectra in (d).

a

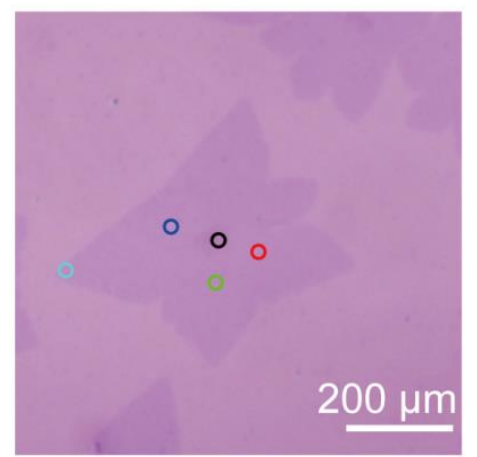

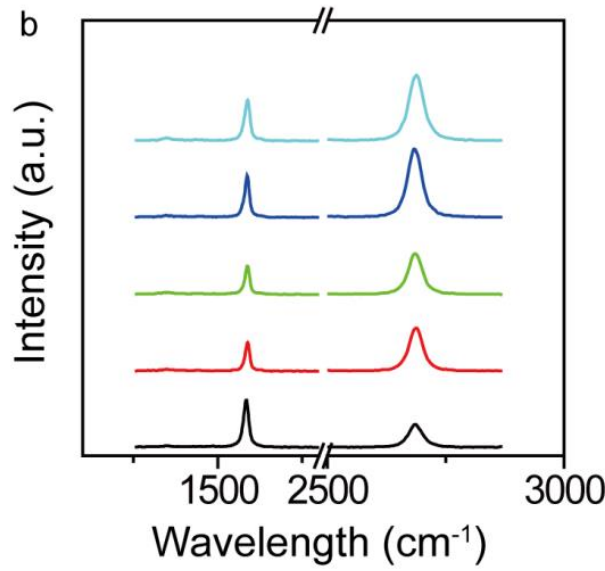

Figure S14. Optical image and Raman spectra of graphene domains in dendritic shape. (a) $\mathrm{OM}$ image of dendritic graphene domains transferred onto $\mathrm{SiO}_{2} / \mathrm{Si}$. (b) Raman spectra of the graphene domain from different positions marked by circles in different colors in (a). 

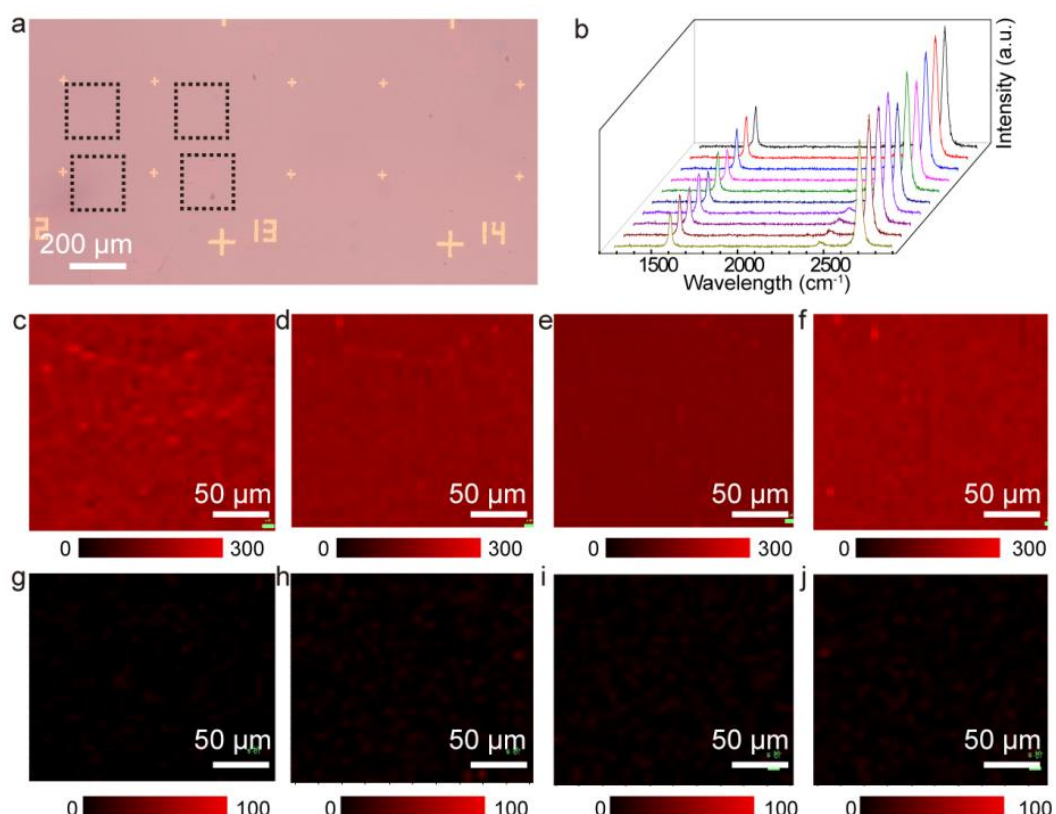

Figure S15. Raman characterization of as-grown graphene transferred onto $\mathbf{S i} / \mathbf{S i O}_{2}$. (a) The $\mathrm{OM}$ image of continuous as-grown graphene transferred onto $\mathrm{Si} / \mathrm{SiO} 2$ substrate. (b) Single-point Raman spectra collected at 10 locations selected randomly. (c-j) Raman mapping of the marked region in (a). (c-f) signals around 1585 $\mathrm{cm}^{-1}$. (g-j) signals around $1350 \mathrm{~cm}^{-1}$.
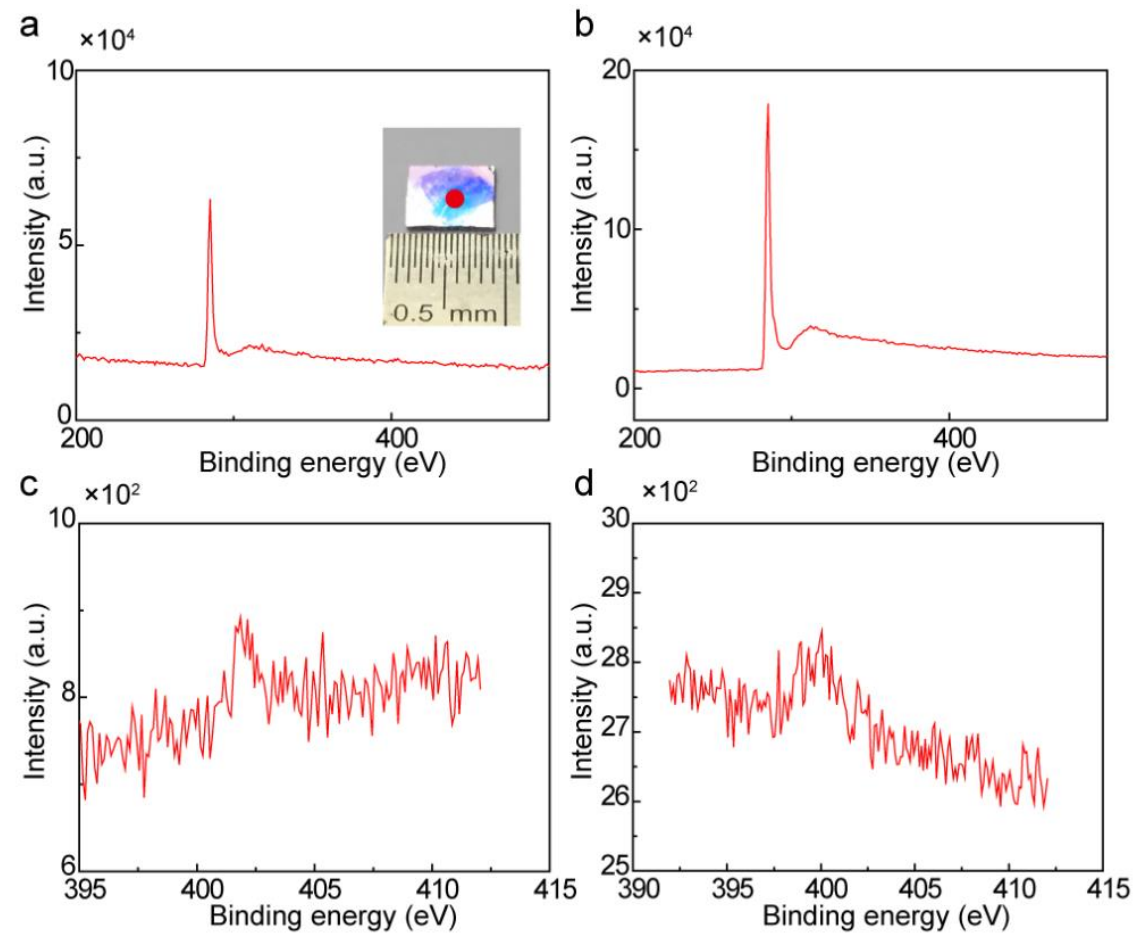
Figure S16. XPS characterization of as-grown graphene transferred onto $\mathrm{Si} / \mathrm{SiO}_{2}$. $(a, b)$ The low resolution survey of XPS spectrum of continuous as-grown graphene transferred onto $\mathrm{Si} / \mathrm{SiO}_{2}$ substrate five times (a) and ten times (b). Inset: the photograph of the graphene films after transferred onto $\mathrm{Si} / \mathrm{SiO}_{2}$ substrate ten times. (c, d) N 1s XPS spectrum of continuous as-grown graphene transferred onto $\mathrm{Si} / \mathrm{SiO}_{2}$ substrate five times (c) and ten times (d).
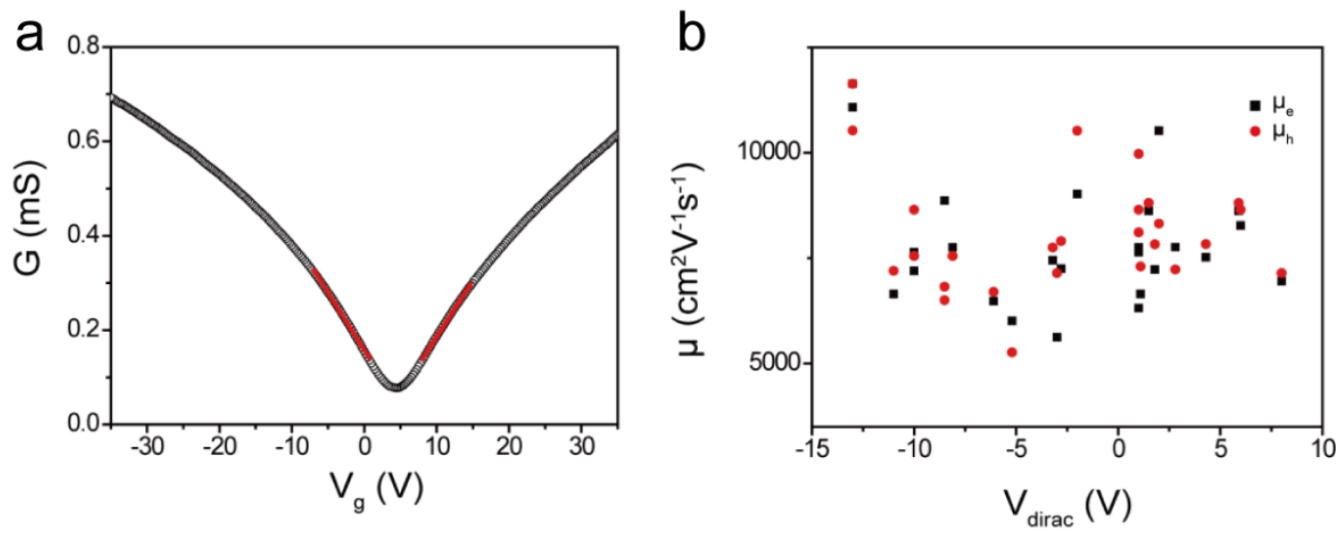

Figure S17. The statistics of carrier mobilities using linear fitting. (a) A typical plot of conductivity as a function of gate voltage in one device at $300 \mathrm{~K}$. (b) The statistics of carrier mobilities and Dirac point positions of 26 devices using linear fitting. Electron and hole mobility are pictured in black and red color, respectively. 

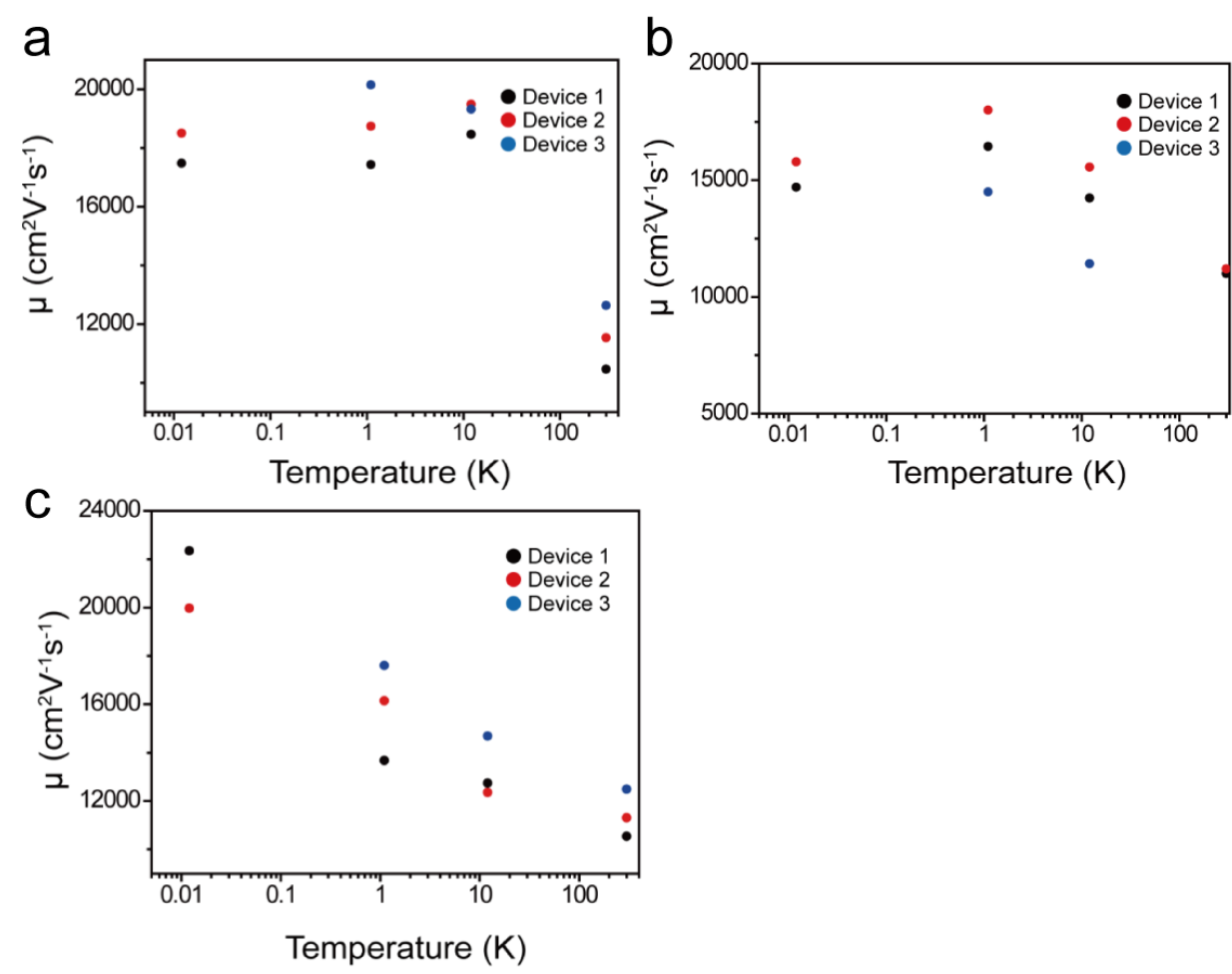

Figure S18. Electrical transport properties of large single-crystal graphene domain measured by ${ }^{3} \mathrm{He} /{ }^{4} \mathrm{He}$ dilution refrigerator. Temperature dependence of FET mobilities of three devices using nonlinear fitting (a) and linear fitting (electron mobility (b), hole mobility (c)), respectively.
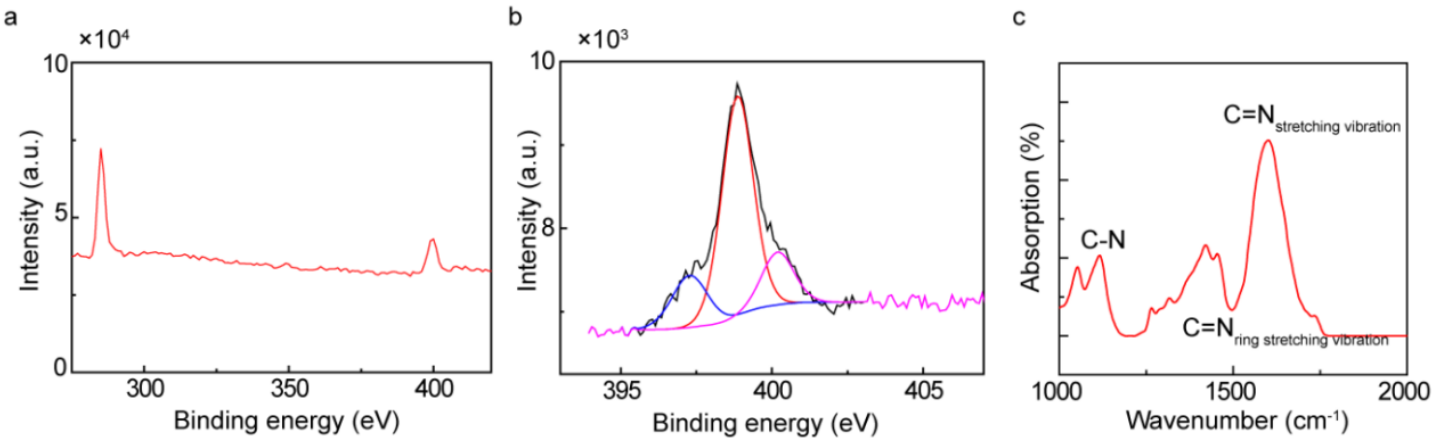

Figure S19. Spectroscopic characterization of carbon- and nitrogen-containing species formed by decomposition of melamine. (a) The low resolution survey of XPS spectrum of carbon- and nitrogen-containing species on the $\mathrm{Cu}$ foil. (b) $\mathrm{N} 1 \mathrm{~s}$ XPS spectrum of carbon- and nitrogen-containing species on the $\mathrm{Cu}$ foil. (c) IR 
spectrum of carbon- and nitrogen-containing species.
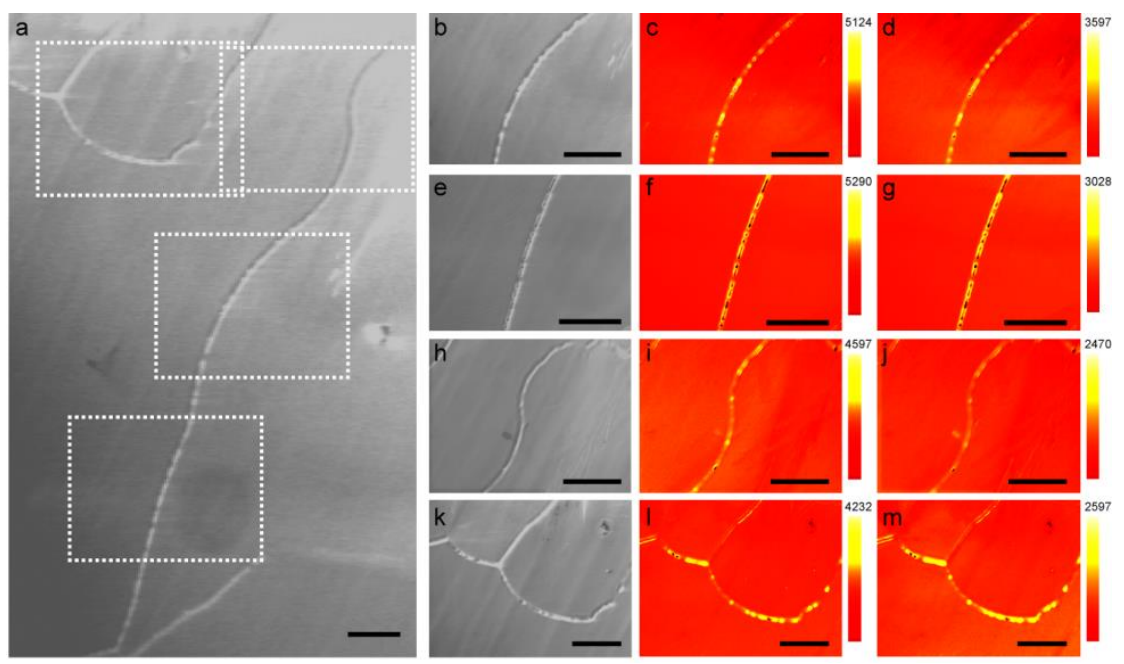

Figure S20. The spatially resolved elemental analyses of copper surface after pretreatment. (a) SEM image of copper surface after melamine pretreatment. (b, e, h, k). Enlarged SEM image of copper surface marked in (a). (c, f, i, l) AES C surface mapping of the area marked in (a). (d, g, j, m) AES $\mathrm{N}$ surface mapping of the area marked in (a). The scale bars are $100 \mu \mathrm{m}$.
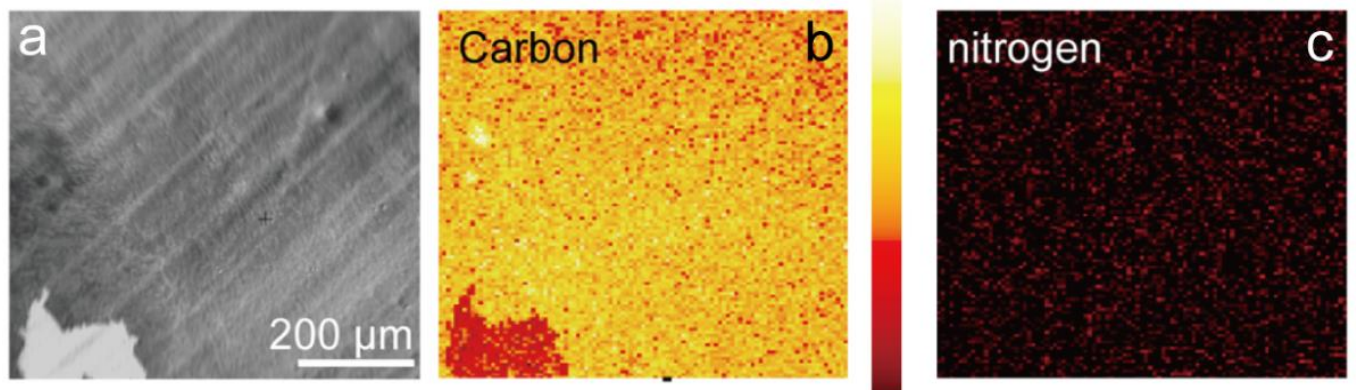

Figure S21. The spatially resolved elemental analyses of copper surface when graphene is almost fully covering copper surface. (a) SEM image of morphology of copper when graphene is almost fully covering copper surface. The pretreatment 
time is set to $10 \mathrm{~min}(\mathbf{b})$. AES C 1s surface mapping of the area in (a). (c) AES N 1s surface mapping of the area in (a). Note that, the intensity of nitrogen signal less than 80 is caused by the background noise indicating no nitrogen was found in this sample. 